\title{
The Impact of Teaching Resiliency on Students' Happiness and Defense Style
}

\author{
Ronak Maroufi \\ Department of Educational Psychology, Kish International Campus \\ University of Tehran, Kish, Iran \\ Email: r.maroufi1987@gmail.com
}

Received: June 14, 2016 Accepted: July 16, 2016 Published: July 28, 2016

doi:10.5296/ijld.v6i3.9795 URL: http://dx.doi.org/10.5296/ ijld.v6i3.9795

\begin{abstract}
The present study was aimed to examine the effect of teaching resiliency on students' happiness and defense style. It was practical in terms of objective; and it was survey-descriptive in terms of data collection method. The statistical population consisted of all male high-school first-grade students (430 individuals) of Tehran's fourth region, from 2015 to 2016. From them, 181 individuals were selected as sample size, using stratified random sampling and Morgan table. Then they were given questionnaires. The present research tool consisted of Bartone's et al Resiliency models (2009), Wood's et al happiness (2010), and Walsh's et al defense style (2010). Analysis of data was done using Structural Equation Modeling method and AMOS 20 software in two sections: measurement model and a structural section. In the first section, technical features of questionnaires were examined by AMOS software. In the second section, significance coefficients of the software were used in order to examine research hypotheses. Research results approved of the positive, significant effect of teaching Resiliency on male students' happiness and defense style in statistical population.
\end{abstract}

Keywords: Resiliency, Happiness, Defense style, Extroversion 


\section{Introduction}

It can be said that the term "resiliency" has entered Iran's psychology literature very recently. Hence, it is a young approach in our country. However developed countries have long focused on identifying factors affecting resiliency, and also on using plans based upon resiliency in different contexts such as educational progress, prevention of drug abuse, child abuse, and crime. Results obtained from implementation of these plans have been successful in different settings such as schools, families, and social settings (Sheikh-al-Eslami, 2009). For resiliency, various definitions have been presented by scholar and experts. Resiliency can be referred to as successful adaptation to threatening conditions (Izadinia and Amiri, 2010), resistance to hardships (Lazarus and Flakman, 1984), sustenance of mental and physical welfare (Joyce et al, 2010), flexibility when facing problems (Muntean et al, 2012), ability to overcome difficulties (Jackson et al, 2007), process of successfully confronting problems (Chong and Cam, 2012), and stressful situations (Jafari et al, 2010), all of which emphasize humans' capacity for resistance to hardships. In other words, resiliency has been defined as individuals' abilities to adapt to hardships; these abilities include personal eligibility, trust in internal forces, and acceptance of changes as positive factors and spiritual effects (Bitsika et al, 2010). Despite the many definitions for resiliency, we can refer to three qualities which are seen in most definitions: favorable results in spite of being in risky situations, constant eligibility in stressful conditions, and recovery after strike (Masten et al, 1990; according to Sheikh-al-Eslami, 2009). Development of resiliency can prevent many educational problems such as dropping-out which stems from lack of resiliency. In this regard, many studies have shown that with resiliency playing a role education, those students with more likelihood of failure and dropping-out cope with tasks better and reach higher levels of education (Southwick et al, 2005). Teaching resiliency can affect certain aspects of individuals' psychological features (Siyez and Savi, 2010). One of the features which has been discussed in the present study is "happiness". According to Breener, level of happiness and satisfaction in individuals has a direct relationship with their attitudes to life; and this means that the more satisfied individuals are with their surrounding and events, the happier they become; if they feel less satisfied, they will feel less happy (Lucas et al, 2003). This clearly shows that there is a direct relationship between happiness, personality, and success. Some researchers believe that happiness is the same as extroversion or consistency in Eysenck's theory; and extroversion is the strongest factor of happiness. Diener (2002) believes that happiness is an evaluation of oneself and personal life, including components such as life satisfaction, emotions, positive behavior, absence of depression, and absence of anxiety; and its different aspects are in the form of cognitions and emotions. Happiness has an important effect on individuals' success. Happy individuals have an optimistic attitude to realities and events, and take advantage from events instead of negative entrenchment. Proper use of happiness is an important aspect of optimistic psychology (Sligman et al, 2005).

It is not easy to identify factors which help to increase happiness (Diener, 2002). Having fun might sometimes lead to happiness. Getting involved with some external issues leads to happiness, and some others lead to stress. Differences in individuals' happiness might be related to personal differences, which are to some extent rooted in genetics. In addition, there 
is no doubt that some environmental settings lead to happiness and provide opportunities which lead to happiness (Hornung, 2006). Considering the above-mentioned material, it is obvious that many psychological variables, which have a clear relationship with the function of safety system, are part of happiness; and studies have shown a significant relationship between happiness and physical health. Therefore, it can be concluded that those who care about their physical health and try to take safety measures have more happiness (Graham, 2008; Piqueras et al, 2011). Another concept of psychology, which can be affected by resiliency, is defense style when facing imbalances (Bitsika et al, 2010; Vulpe, 2012). Vulpe (2012) sees defense as a cognitive-behavioral effort to confront stressful situations. According to Derveek (2012), defense is a purposeful and industrious response to events which cause mental pressure. Lee et al (2012) have defined defense styles as a set of cognitive-emotional actions which are used in order to respond to substantial issues. These efforts are made to reach balance; and this can solve problems or helps to adapt to problems and find solutions. Sarason (1989) believes that defense is how we overcome problems. On the other hand, Folken and Lazlerus define defense based on situational conditions and successful management of stressful situations. Other definitions are often a combination of these two definitions and they are on a continuum (Finn, 2003). In this study, problem-focused, emotion-focused, and avoidance-focused defense styles are examined. Individuals with problem-focused defense style use cognitive skills in order to confront problems. Hence, defense methods are examined directly; normally after a proper solution is found, psychological satisfaction is attained (Folkman and Moskowitz). Emotion-focused defense refers to confronting emotions resulting from threat sources, and it is associated with coming to terms or reducing negative emotions; and it is done in order to balance emotions and to control emotional reactions. Avoidance-focused defense style is more associated with avoiding critical situations (Herman et al, 1995).

Reviewing the literature, we encounter some resiliency studies; some of them, which are close to the present study, are summarized below. Research results for resiliency refer to positive changes in cognitive beliefs, cognitive reconstructions, and emotion management and control, which result in more happiness (Togad et al, 2004). Hosseini Torshizi (2010) did a research called "Examination of the effect of teaching resiliency and defense skills on female students' mental health." Their research results showed that progress motivation in students who have received resiliency lessons is more than in those who have not received defense lessons. In his study, Vulpe (2012) has examined positive relationships, defense and resiliency strategies. He stated that positive emotions and defense strategies play a positive role in individuals' resiliency. Rajabi Moghaddam and Bdjari (2011) stated that there is a positive relationship between happiness and problem-solving-focused defense style; and that there is a negative relationship between happiness and avoidance-focused defense style.

Chan (2000) examined the relationship between resiliency and psychological stresses in Chinese adolescents; and he showed that students with high resiliency do not face more positive events, but they face substantially less negative events. In addition, students with low resiliency, compared to those with high resiliency, use substantially more avoidance-focused coming-to-terms and passive methods. Chan (2003) stated that resiliency plays an adjusting 
role in the relationship between stress and depletion; and this has a significant positive effect on teachers' success. Bittner et al (2010) stated that there is a significant relationship between defense strategies and confronting stressful situations. In other words, from defense strategies, issue-focused strategy has a positive significant relationship with the type of confronting stressors; and it has a negative significant relationship with avoidance-focused strategy. DiCorcia and Tronick (2012) examined resiliency strategies in connection to stress and confronting stressful situations. Their research results express the positive effect of resiliency on fighting stress. Salehi Nejad and Besharat (2010) stated that there is a positive significant relationship between resiliency and mental health. Individuals with higher resiliency have better mental health; and when facing critical situations, they act more effectively. Results obtained from a study conducted by Beasley et al (2003) show that resiliency reinforces issue-focused defense style, helping individuals to better cope with daily stress. Johnson et al (2010) referred to the effect of resiliency on the selection of the three styles of defense. Individuals who had less resiliency confronted stressors mainly through avoidance-focused style. Fredrickson (2004) showed that teaching resiliency is a method affecting adolescents' depression.

Considering theoretical concepts and research background, effect of teaching resiliency on students' happiness and defense styles was examined based on the following hypotheses:

1) Teaching resiliency affects students' happiness.

2) Teaching resiliency affects male students' defense styles (issue-focused, emotion-focused, and avoidance-focused).

\section{Methodology}

The present study was practical in terms of objective; and in terms of data collection method, it was survey-descriptive. In order to prove hypotheses and realize findings, certain questionnaires were used. On the other hand, the present study is a quantitative research in terms of collected data. Hence, certain questionnaires were handed to students in order to collect their comments. In addition, since the present study examines a cause-and-effect relationship, research methodology was causal in terms of the relationship between variables; to comprehensively examine the conceptual model of the research, Structural Equation Modeling method was used. Structural Equation modeling is composed of two sections: measurement model and structural model. And model variables are divided into two classes: latent and observed variables (Hooman, 2009, page 19). In the present study, teaching resiliency, happiness, and defense styles are latent variables; and questions that are used in order to evaluate latent variables are observed variables, whose indexes are considered.

\subsection{Statistical Population, Sampling, and Sample Size}

The statistical population consisted of all male high-school first-grade students of Tehran's fourth region (about 430 individuals). Sample size was selected using stratified sampling method. First, all high schools of Tehran's fourth region were divided into certain classes based on provincial education regions; then, from the classes, certain schools were selected; and from the schools, sample was selected using Morgan table. Finally, 180 individuals were 
selected as sample size. In order to be sure of analysis results, 200 questionnaires were used, from which 178 questionnaires were handed to students (rate of response: $89 \%$ ).

\subsection{Data Collection Tool}

Research questionnaire was composed of three sections: defense, happiness, and defense style. Bartoneet's et al resiliency model (2009), Wood's et al happiness (2010), and Walsh's et al defense style (2010) in order to provide questionnaires. The first section (teaching resiliency) consisted of 12 questions which evaluate compatibility, defense, and flexibility when facing problems. The second section (happiness) included 18 questions which evaluate satisfaction, extroversion, and optimistic attitude. Finally, the third section (defense styles) included 9 questions which evaluate issue-focused, emotion-focused, and avoidance-focused styles.

\subsubsection{Reliability}

In order to examine reliability, AMOS 20 software was used. Using this software, through factorial loads and calculation of correlation coefficient of an item's indexes, reliability is examined. If reliability equals 0.4 or if it is greater than 0.4 (Hulland, 1999), it will be acceptable for measurement model. In the present study, results related to reliability showed that all questions had a factorial load of greater than 0.4 ; hence, there was no need to remove any questions.

\subsubsection{Validity}

Validity of the questionnaire was calculated by convergent and divergent validity, which are exclusive to Structural Equation modeling. To evaluate convergent validity, AVE (Average Variance Extracted) was used. The results of this criterion have been presented in table (1) for research variables.

Table (1): Results of convergent validity of research variables

\begin{tabular}{|c|c|c|c|c|c|c|c|c|c|}
\hline Variabl & compatibili & defens & flexibilit & satisfactio & extroversi & Optimisti & Issue-focus & Emotion-focus & Avoidance-focus \\
ed & ty & e & y & $\mathrm{n}$ & on & c attitude & ed & ed \\
\hline AVE & 0.655 & $\begin{array}{c}0.67 \\
8\end{array}$ & 0.611 & 0.703 & 0.521 & 0.605 & 0.533 & 0.711 & 0.567 \\
\hline
\end{tabular}

Desired value for acceptance of AVE is 0.5 (Hulland, 1999). As it can be seen in the above table, all values of AVE related to items are greater than 0.5; and this shows that convergent validity of the present study is acceptable.

In divergent validity section, indexes of an item and indexes of other items are compared. This is calculated through comparison of each item's AVE square with correlation coefficients between items. Results of AMOS software's output showed that each item's AVE square was greater than other item's correlation coefficients; this shows that divergent validity of items is acceptable. 


\section{Macrothink

\section{Analysis of Data and Research Findings}

In the next stage, using AMOS 20 software, Confirmatory Factor Analysis was done in order to evaluate measurement models; and causal Beta coefficients examination was done in order to evaluate the structural section of the model. If the following conditions hold, model has proper fitting: significance level obtained from Chi Square test (P-value) was greater than 0.05. Proportion of Chi Square to freedom degree is less than 3. Root Mean Square Error of Approximation (RMSA) is less than 0.05. Comparative fitting index value (CFI), fitting index (GFI), adjusted fitting index (AGFI), and non-soft fitting index (NNFI) are greater than 0.9 (Jorsgok \& Sorbom, 1996). As it can be seen from figure 1, P-value equals 0.001, RMSA equals 0.013, and Chi Square -to-freedom degree (41) ratio (101.021) reaches 2.46, which is smaller than 3. In addition, other AMOS results showed that CFI equals 0.902; calculated value of $\mathrm{Z}$ is greater than 1.96; and values of GFI and AGFI were calculated to be 0.914 and 0.942. Therefore, measurement models related to the three main items have acceptable fitting. On the other hand, output of AMOS software (figure 1) shows that relationships between items are significant, and research hypotheses are approved. 


\section{Macrothink

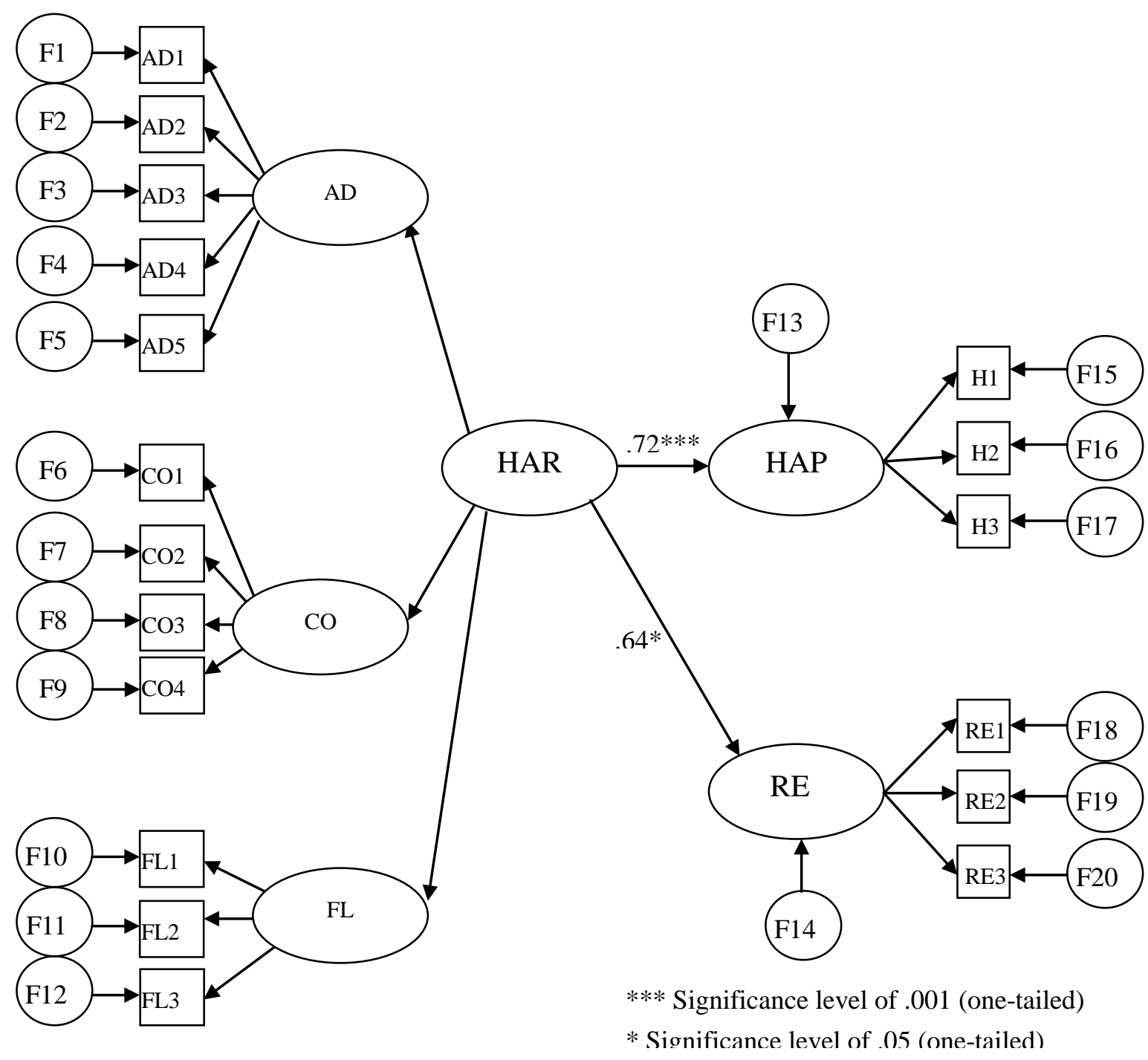

Chi-Square $=101.021, \mathrm{DF}=41, \mathrm{P}$-value $=0.001, \mathrm{RMSEA}=0.013$

Fig. 1: Structural Equation Model

HAR=Hardiness, $\mathrm{AD}=$ Adaptability, $\mathrm{CO}=$ Confront, $\mathrm{FL}=$ Flexibility, $\mathrm{HAP}=$ Happiness, $\mathrm{RE}=$ Resilience

Based on the above tigure, in the output of AMUS sottware (tigure 1), the relationship between teaching resiliency and its dimensions with happiness is significant and direct; this means that teaching resiliency has a positive significant effect on students' happiness; according to standard coefficients of AMOS software output, 72 percent of happiness changes are predicted by teaching resiliency. In addition, teaching resiliency has a positive significant effect on students' defense styles; and according to AMOS software output, 64 percent of defense style changes are predicted by teaching resiliency. Table 2 shows these coefficients. When values of " $t$ " are in an era of +1.96 and -1.96 , the corresponding parameter is significant (Byme, 2001). Values of " $t$ " presented in table 2 show the significance of relationships included in hypotheses. 
Table 2: Results of testing research hypotheses

\begin{tabular}{|c|c|c|c|c|}
\hline hypotheses & $\begin{array}{c}\text { Standardized } \\
\text { coefficients }\end{array}$ & Value of "t" & Result \\
\hline $\begin{array}{c}\text { Teaching resiliency --- } \\
\text { happiness }\end{array}$ & 0.72 & \multicolumn{2}{|c|}{11.82} & Accepted \\
\hline AGFI=0.94 & GFI=0.91 & \multicolumn{2}{|c|}{ RMSEA=0.013 } & \multicolumn{2}{c|}{ Df=41 } & $\chi^{2}=101.021$ \\
\hline $\begin{array}{c}\text { Teaching resiliency --- } \\
\text { defense styles }\end{array}$ & 0.64 & \multicolumn{2}{|c|}{9.54} & accepted \\
\hline AGFI $=0.94$ & GFI $=0.91$ & RMSEA $=0.013$ & Df $=41$ & $\chi^{2}=101.021$ \\
\hline
\end{tabular}

\section{Discussion and Conclusion}

The present study was aimed to examine the effect of teaching resiliency on male high-school first-grade students' happiness and defense styles, in Tehran's fourth region. The effect was examined based on certain hypotheses. In the first hypothesis of the research, which refers to the fact that teaching resiliency affects male students' happiness, results showed that teaching resiliency has been effective in Male high-school second-grade students' happiness, in Tehran's fourth region. This conclusion was in congruence with conclusions drawn by scholars such as Togad et al (2004), Chan (2000); Salehi Nejad and Besharart (2010). This approves of the fact that teaching resiliency affects happiness. In the second hypothesis of the research, we decided to examine the effect of teaching resiliency on male students' defense styles (issue-focused, emotion-focused, and avoidance-focused). Obtained results refer to the positive and significant effect of teaching resiliency on students' defense styles. Obtained results were in line with those obtained by Johnson et al (2010), Chan (2000), Beasely et al (2003), and part of Bittner's et al results (2010). In addition, Studies conducted in this field were in congruence with results of studies done by Vulpe (2012), Hosseini Torshizi (2010), Togad et al (2004), and Chan (2003); these scholars, who have examined the effect of resiliency on individuals" capacities and abilities to adapt to different environments, refer to the fact that it can play a significant role in individuals' adaptability to challenging life conditions. Teaching resiliency, especially in adolescence and young age, can considerably make today's lives easier. By paying attention to such lessons, schools can lead students to healthier lives. Considering the results obtained from this research, it is recommended that school officials especially managers pay more and more attention to resiliency and encourage schools and educational centers to offer such lessons. It is also recommended that:

1) 'They must examine the role of educational factors in different students' resiliency.

2) They must plan and hold educational workshops for adolescents in order to enhance positive psychological capital (hope, self-efficacy, optimism, and resiliency). In conclusion, they must examine its effect on organizational variables such as job satisfaction and so forth.

3) Despite the fact that resiliency possesses factors which convince some scholars of the fact that it is inherent, educational intervention for empowering children, adolescents, 
and young adults can be effective in four fields such as society, family, institutions, and media; finally, doing longitudinal studies in this field in our country can lead to gathering more information connected to positive psychological capital, which helps individuals in future.

\section{References}

Hosseini Torshizi, Z. (2009), examination of the role of resiliency and defense skills in students' mental health, MA thesis, Sanandaj's Islamic Azad University.

Sheikh-al-Eslami, A. (2009). Examination of the relationship between resiliency and self-esteem with male and female first-grade high-school students' educational progress in Shahriar's high schools, MA thesis, Psychology and Education College, Allameh Tabatabaie University.

Hooman, H.A. (2010). Modeling of cultural equations using LISREL software. Tehran: SAMT Publications.

Bartone, P. T., Eid, J., Johnsen, B. H., Laberg, J. C., \& Snook, S. A. (2009). Big five personality factors, hardiness, and social judgment as predictors of leader performance. Leadership \& Organization Development Journal, 30(6), 498-521.

Beasley, Margaret; Ted, Thompson; Davidson, John. (2003). Resiliency in response to life stress: the effects of coping style and cognitive hardiness. Personality and Individual Differences 34: 77-95.

Bitsika, V. Sharply, C. F. Peters K. (2010). How is resiliency associated with anxiety and depression? Analysis of factor score interactions within a homogeneous sample. The German Journal of Psychiatry, 13, 9-16.

Bittner, Ava K; O.D., a Lori Edwards, M.P.H., b and Maureen George. (2010). Coping strategies to manage stress related to vision loss and fluctuations in retinitis pigmentosa. Optometry, 81:461-468.

Byrne, B. M. (2001). Structural equation modeling with AMOS: Basic concepts, applications, and programming. Mahwah, NJ: Erlbaum.

Chan, D. W. (2000). Dimensionality of hardiness and its role in the stress-distress relationship among Chinese adolescents in Hong Kong. Journal of youth and adolescence, 29(2), 147-161.

Chan, D. W. (2003). Hardiness and its role in the stress-burnout relationship among prospective Chinese teachers in Hong Kong. Teaching and Teacher Education, 19(4), 381-395.

Cheung, C. k; Kam, P. K. (2012). Resiliency in older Hong Kong Chinese: Using the grounded theory approach to reveal social and spiritual conditions. Journal of Aging Studies 26 (2012) 355-367. 


\section{MInstitute Macrothink $_{\text {Int }}$}

International Journal of Learning and Development

ISSN 2164-4063

2016, Vol. 6, No. 3

Derveek, Shelley M.C; H.H.F. Derkx, Else de Haan; Marc A. Benninga; Frits, Boer (2012). Emotion awareness and coping in children with functional abdominal pain: A controlled study. Social Science \& Medicine 74 (2012) 112e119.

DiCorcia, Jennifer; TronickA, Ed. (2011). Quotidian resiliency: Exploring mechanisms that drive resiliency from a perspective of everyday stress and coping. Neuroscience and Biobehavioral Reviews, 35: 1593-1602

Diener، E. (2002). Frequently Asked question (FAQ'S) about subjective well-being (Happiness and life satisfaction). A printer for report and new comers. http://www./s.psych.uivc.edu/-ediener/fag.html.

Finn, D. (2003). The "Employment-first" Welfare State: Lessons from the New Deal for Young People. Social Policy \& Administration, 37(7), 709-724.

Folkman, S. \& Moskowitz, J.T. (2000). Positive affect and the other side of coping. American Psychologist, 647-654.

Fredrickson, B. L. (2004). The broaden-and-build theory of positive emotions. PHILOSOPHICAL TRANSACTIONS-ROYAL SOCIETY OF LONDON SERIES B BIOLOGICAL SCIENCES, 1367-1378.

Graham, C. (2008). Happiness and health: Lessons - and questions-for public policy. Health Affairs, 27(1), 72-87.

Herman-Stahl, M.A., Stemmier, M. \& Petersen, A.C. (1995). Approach and avoidant coping: Implications for adolescent mental health. Journal of Youth and Adolescence, 24(6), 649.

Hornung, B. R. (2006). Happiness and the pursuit of happiness: A sociocybernetic approach. Kybernetes, 35(3/4), 323-346.

Hulland, J. (1999). 'Use of partial least squares (PLS) in strategic management research: A review of four recent studies. Strategic Management Journal, 20(2), pp. 195-204.

Izadinia, N; Amiri M (2010). A study of relationship between suicidal ideas, depression, anxiety, resiliency, daily stresses and mental health among Tehran university student. Procedia Social and Behavioral Sciences 5 (2010) 1515-1519.

Jackson, D., Firtko, A., \& Edenborough, M. (2007). Personal resiliency as a strategy for surviving and thriving in the face of workplace adversity: a literature review. Journal of Advanced Nursing, 60(1), 1-9.

Jafar,I; Eskandari, H; Sohrabi, F; Delavar, Ali; Heshmati, Rasoul. (2010). Effectiveness of coping skills training in relapse prevention and resiliency enhancement in people with substance dependency. Procedia Social and Behavioral Sciences 5:1376-1380.

Johnson J., P.A, Gooding, A.M. Wood, N. Tarrier. (2010). Resiliency as positive coping appraisals: Testing the schematic appraisals model of suicide (SAMS). Behaviour Research and Therapy 48: 179-186 
Joreskog, K. \& Sorbom, D. (1996). Structural Equation Modeling with the SIMPLIS Command Language. Chicago, IL: Scientific Software International, Inc.

Joyce, F. V., Rhodes, D. L., \& Hey, D. W. (2010). Perceived Personal and Social Competence: Development of Valid and Reliable Measures. The Health Educator, 42(1), 19.

Lazarus, R, S; Folkman, S. (1984). Stress, appraisal, and coping .New York: Springer.

Li, Ryan; Cooper, Claudia; Jonathan, Bradley; Amanda, Shulman; Gill Livingston. (2012). Coping strategies and psychological morbidity in family careers of people with dementia: A systematic review and meta-analysis. Journal of Affective Disorders 139: 1-11.

Lucas, R. E., Clark, A. E., Georgellis, Y., \& Diener, E. (2003). Reexamining adaptation and the set point model of happiness: reactions to changes in marital status. Journal of personality and social psychology, 84(3), 527.

Muntean, An; Roxana, Ungureanu; Patricia, Runcan. (2012). the schools role in building up the resiliency of adopted children. Procedia - Social and Behavioral Sciences 46 (2012) 331 334.

Piqueras, J. A., Kuhne, W., Vera-Villarroel, P., van Straten, A., \& Cuijpers, P. (2011). Happiness and health behaviours in Chilean college students: A cross-sectional survey. BMC public health, 11(1), 443.

Rajabimoghaddam, Sara; Farah Bidjari, Azam (2011). The study of relation of happiness rate and styles of coping. Procedia - Social and Behavioral Sciences 30 (2011) 2410 - 2415.

Salehi Nezhad, Mohammad Ali; Besharat, Mohammad Ali.(2010). Relations of resiliency and hardiness with sport achievement and mental health in a sample of athletes. Procedia Social and Behavioral Sciences 5: 757-49.

Seligman, M. E., Steen, T. A., Park, N., \& Peterson, C. (2005). Positive psychology progress: empirical validation of interventions. American psychologist, 60(5), 410.

Siyez, Didem M; Savi, Firdevs. (2010). Empathy and self-efficacy, and resiliency: an exploratory study of counseling students in Turkey. Procedia Social and Behavioral Sciences 5: $\quad 459-463$.

Southwick, S. M., Vythilingam, M., \& Charney, D. S. (2005). The psychobiology of depression and resiliency to stress: implications for prevention and treatment. Annual Review of Clinica Psychology, 1, 255-291.

Tugade, M. M., \& Fredrickson, B. L. (2004) Resilient individuals use positive emotions to. Bounce back from negative emotional experiences. Journal of Personality and Socia Psychology, 86, 320-333.1

Vulpe, Alina; Dafinoiu, Ion. (2012). Positive emotions, coping strategies and ego-resiliency: A mediation model. Procedia - Social and Behavioral Sciences 33, 308 - 312.

Walsh, W. A., Dawson, J., \& Mattingly, M. J. (2010). How are we measuring resiliency 


\section{Macrothink}

International Journal of Learning and Development

ISSN 2164-4063 2016, Vol. 6, No. 3

following childhood maltreatment? Is the research adequate and consistent? What is the impact on research, practice, and policy? Trauma, Violence, \& Abuse, 11(1), 27-41.

Wood, A. M., Taylor, P. J., \& Joseph, S. (2010). Does the CES-D measure a continuum from depression to happiness? Comparing substantive and art factual models. Psychiatry Research, 177(1), 120-123.

\section{Copyright Disclaimer}

Copyright for this article is retained by the author(s), with first publication rights granted to the journal.

This is an open-access article distributed under the terms and conditions of the Creative Commons Attribution license (http://creativecommons.org/licenses/by/3.0/). 